\title{
ACUTE APPENDICITIS REVIEW
}

KEY WORDS: Appendicitis, appendix, Alvarado

\section{Erazo Hoyos \\ Pablo David* \\ Andrade Villalva \\ María Fernanda}

Independent investigator. ${ }^{*}$ Corresponding Author

\section{Leon}

Guamanquispe

Independent investigator.

\section{Tannia Elizabeth}

\section{Fiallos}

Santamaría Fátima Gissela

\section{Aguiar Flores Gloria Estefanía}

Independent investigator.

Acute Appendicitis ( $A A)$ is an inflammatory process of the cecal (or vermiform) appendix, frequently due to the obstruction of the lumen of the appendix. It is also associated with a high risk of developing ileus, peritonitis, abdominal abscess if it does not have a fast and timely treatment. Technological tools such as CT, ultrasound and MRI are currently the ideal complement for the diagnosis of AA, which is initially based on the clinic with the Alvarado Scale.

\section{INTRODUCCION}

The term appendix -itis was coined in the 1540 s to describe an elongated outgrowth of an internal organ.

Appendicitis was first described in 1759 by Metiever, but it was believed at the time that the appendix was not the origin of the disease process and it was termed perityphlitis, typhlitis, paratyphlitis, or extra-peritoneal abscess of the right iliac fossa.

From the early days onwards, the timeliness of diagnosis was considered to be critical to reducing mortality rates related to appendicitis. The clinical diagnosis was developed to determine if appendicitis is present.

Charles McBurney labeled the precise spot to be 1.5-2 inches from the right anterior superior spinous process of the ilium on a line drawn to the umbilicus. We now call this clinical sign the McBurney's point.

\section{EPIDEMIOLOGY}

Appendicitis occurs most commonly between the ages of 10 and 20 years and it has a male-to-female ratio of $1.4: 1$.

The lifetime risk is $8.6 \%$ for males and $6.7 \%$ for females in the United States. Studies have indicated an association between acute appendicitis and the manifestation of colorectal cancer. In fact, $2.9 \%$ of patients who suffered from acute appendicitis were found to have colorectal cancer compared to $0.1 \%$ of those who did not.

Sisalima et al, reports in his Thesis 267 patients admitted with a diagnosis of acute appendicitis in 2 hospitals in CuencaEcuador; the prevalence of complicated appendicitis was $38.2 \%$. It was observed that the associated factors were initial misdiagnosis (PR 1.57 CI: 1.16 - 2.14; p 0.01), and time elapsed from the onset of symptoms to arrival at the hospital greater than 12 hours (PR2.19 CI: 1.34-3.59; 0 0.00).

The Alvarado Scale was proposed in 1986 by the Colombian 8 doctor Alfredo Alvarado, after the results obtained through a retrospective study with 305 patients who underwent surgery for acute appendicitis and, according to Motta et al. (2017) "tabulated the symptoms and signs of the disease as well as the laboratory results of the patients."

With this work, he developed a scale that determines 8 parameters or predictive clinical characteristics, grouped under the acronym MANTRELS (for its acronym in English) assigning six of these the value of 1 point, and the other two distinctions the value of 2 points, all these addends give a total of 10 points.

\section{DIAGNOSIS}

The initial presentation involves periumbilical colicky pain around the midgut.

Localized pain coincides with the parietal peritoneum irritation.

The pain intensifies over a period of 24 hours, accompanied by nausea, vomiting, and loss of appetite.

In $3.5 \%$ of appendicitis presentations, left iliac fossa deep palpation elicits pain in the right iliac fossa, which is termed Rovsing's sign.

If the patient is found to have a positive Rovsing's sign, a barium swallow is then employed to confirm the diagnosis. Barium swallow was initially found to be $95 \%$ accurate.

Currently, diagnosis is made by helical CT and graded compression color Doppler ultrasonography.

A diagnosis can be made based on persistent right lower quadrant pain and a visualized appendix greater than $6 \mathrm{~mm}$ in diameter.

New studies point toward the efficacy of MRI, indicating 96$96.8 \%$ sensitivity and a $96-97.4 \%$ specificity. Enabling this 
new modality will allow for patients such as children to avoid exposure to radiation and intravenous contrast medium, while still providing diagnostic accuracy. This finding foresees future first-line testing in children and possibly the general population.

The Alvarado scoring system is one of the most frequently used scoring systems to determine the need for surgical intervention for appendicitis, that uses: Migratory right iliac fossa pain, Nausea/vomiting, Anorexia, Tenderness in right iliac fossa, Rebound tenderness in right iliac fossa, Elevated temperatura, Leukocytosis, Shift to the left of neutrophils.

Scores of 1-4 indicate "discharged home", scores of 5-6 signify being "observed", and scores of 7-10 indicate the need to "undergo emergent surgery"

\section{TREATMENT}

Early treatment of appendicitis focused on surgery. In 1883, Abraham Groves performed the first elective appendectomy. In 1886, Reginald Fitz published the first paper describing early diagnosis and treatment of appendicitis.

In 1894, Charles McBurney described an incision parallel to the right rectus muscle oblique at approximately 1-4 inches.

Four advantages have been described with respect to using this technique: it provides easy direct access to the inflamed organ, drains can be placed laterally with sutures needed only on the peritoneum, the incision can be closed without risk of hernia, and, finally, access to cases of obstruction can be obtained without passing through additional structures.

Lower morbidity was found with a conservative route compared to the operative route and Antibiotics were added to prevent infections.

Sulfanilamide was first used in 1940, and it was administered intraperitoneally as a local antibiotic.

In the 1990s, European investigators revisited the treatment of appendicitis by using antibiotics. It was found that $80 \%$ of preoperative diagnosis of appendicitis was correct with only one in six found to be having perforated appendicitis.

In the United States, conservative management with antibiotics prior to surgical intervention has demonstrated positive results.

Forgoing or postponing surgical intervention enables treatment without surgical complications and have demonstrated patients being capable of an expedited return to work in comparison to surgical intervention.

Uncomplicated appendicitis can be delayed in the hospital by $12-24$ hours.

On the other hand, early surgical intervention is thought to be associated with a lower risk of perforation.

Conservative treatment with antibiotics was found to be $18 \%$ less effective than surgical treatment.

Laparoscopic appendectomy is another modality that enables same-day discharge; it was introduced by Semm in 1983.

\section{DIFFERENTIAL DIAGNOSIS}

The differential diagnosis of appendicitis is that of an acute abdomen by Intestinal obstruction, Intussusception, Perforated peptic ulcer, Meckel's diverticulitis, Right pyelonephritis, Ruptured ovarian follicle, Terminal ileitis, Porphyria, . At the extremes of age, the threshold for referral for further assessment should be low because of the high mortality associated with delayed presentation or diagnosis.

\section{TIMING OF SURGERY}

A recent retrospective study found no significant differences in complications between early (less than 12 hours after presentation) or later (12-24 hours) appendicectomy.

This does not, however, take into account the actual time from the onset of symptoms to presentation, which can have a bearing on the rate of perforation.

After the first 36 hours from the onset of symptoms the average rate of perforation is between $16 \%$ and $36 \%$, and the risk of perforation is $5 \%$ for every subsequent 12 hour period. Once a diagnosis is made, appendicectomy should therefore be done without any unnecessary delays.

\section{WHAT ARE THE COMPLICATIONS}

Appendicectomy is a relatively safe procedure with a mortality rate for non-perforated appendicitis of 0.8 per 1000 . The mortality and morbidity are related to the stage of disease and increase in cases of perforation; mortality after perforation is 5.1 per 1000 .

As stated above, the average rate of perforation at presentation is between $16 \%$ and $30 \%$, but this is significantly increased in elderly people and young children, in whom the rate can be up to $97 \%$, usually because of a delay in diagnosis.

The increased mortality and morbidity associated with perforation has been used as justification for high rates of negative appendicectomy, quoted as between $20 \%$ and $25 \%$.

Despite this, complications can occur after removal of a normal appendix, and the surgical community continues to strive to reduce the numbers of negative procedures.

According to a large historical cohort study, a perforated appendix during childhood does not seem to have a long term detrimental effect on subsequent female fertility.

\section{REFERENCES}

1. Appendix. [Jun;2020 ];https://www.etymonline. com/word/ appendix ? ref = etymonline crossreference

2. II. The indications for early laparotomy in appendicitis. McBurney C. Ann Surg. 1891;13:233-254. [PMC free article] [PubMed] [Google Scholar]

3. Experimental proof of the obstructive origin of appendicitis in man. Wangensteen OH, Dennis C. Ann Surg. 1939;110:629-647. [PMC free article] [PubMed] [Google Scholar]

4. IV. The incision made in the abdominal wall in cases of appendicitis, with a description of a new method of operating. McBurney C. Ann Surg. 1894;20:38-43. [PMC free article] [PubMed] [Google Scholar]

5. Gray H. Pick T, Howden R 1901. Philadelphia, PA: Running Press; 1901 Anatomy,Descriptive and Surgical, 1901 Edition. [Google Scholar]

6. Acute appendicitis. Humes DJ, Simpson J. BMJ. 2006;333:530-534. [PMC free article] [PubMed] [Google Scholar]

7. Acute appendicitis as a sign of a colorectal carcinoma. Arnbjörnsson E.J Surg Oncol. 1982;20:17-20. [PubMed] [Google Scholar]

8. Appendicitis as a manifestation of colon cancer: should we image the colon after appendicectomy in patients over the age of 40 years? Mohamed I, Chan S, Bhangu A, Karandikar S. Int J Colorectal Dis. 2019;34:527-531. [PubMed] [Google Scholar]

9. Acute appendicitis. Campbell JA, McPhail DC. Br Med J. 1958;1:852-855. [PMC free article] [PubMed] [Google Scholar]

10. Use of the barium swallow in the diagnosis of acute appendicitis. Schisgall RM.Am J Surg. 1983;146:663-667. [PubMed] [Google Scholar]

11. Appendicitis at the millennium. Birnbaum BA, Wilson SR. Radiology. 2000;215:337-348. [PubMed] [Google Scholar]

12. Acute appendicitis: sonographic criteria based on 250 cases. Jeffrey RB Jr, Laing FC, Townsend RR. Radiology. 1988;167:327-329. [PubMed] [Google Scholar]

13. A systematic review and meta-analysis of diagnostic performance of MRI for evaluation of acute appendicitis. Duke E, Kalb B, Arif-Tiwari H, Daye ZJ, Gilbertson-Dahdal D, Keim SM, Martin DR. AJR Am J Roentgenol. 2016;206:508-517. [PubMed] [Google Scholar]

14. WSES Jerusalem guidelines for diagnosis and treatment of acute appendicitis. Di Saverio S, Birindelli A, Kelly MD, et al. World J Emerg Surg. 2016;11:34. [PMC free article] [PubMed] [Google Scholar]

15. Application of Alvarado scoring system in diagnosis of acute appendicitis. Khan I, ur Rehman A. http://www.jamc.ayubmed.edu.pk/ index.php/ jamc/article/download/4951/2228.J Ayub Med Coll Abbottabad. 2005; 17:4144. [PubMed] [Google Scholar]

16. How to improve the clinical diagnosis of acute appendicitis in resource limited settings. Alvarado A. World J Emerg Surg. 2016;11:16. [PMC free article] [PubMed] [Google Scholar] 
17. Acute appendicitis: diagnostic accuracy of Alvarado scoring system. Memon ZA, Irfan S, Fatima K, Iqbal MS, Sami W. Asian J Surg. 2013;36:144-149. [PubMed] [Google Scholar]

18. The appendicitis inflammatory response score: a tool for the diagnosis of acute appendicitis that outperforms the Alvarado score. Andersson M, Andersson RE. World J Surg. 2008;32:1843-1849. [PubMed] [Google Scholar]

19. Evaluation of the appendicitis inflammatory response score for patients with acute appendicitis. de Castro SM, Ünlü C, Steller EP, van Wagensveld BA, Vrouenraets BC. World J Surg. 2012;36:1540-1545. [PMC free article] [PubMed] [Google Scholar]

20. The value of scoring systems for the diagnosis of acute appendicitis. Walczak DA, Pawe czak D, ó taszek A, et al. Pol Przegl Chir. 2015;87:65-70. [PubMed] [Google Scholar]

21. Abraham Groves of Fergus: the first elective appendectomy? Harris CW. https://www.ncbi.nlm.nih.gov/pubmed/13711715?report=docsum. Can J Surg. 1961;4:405-410. [PubMed] [Google Scholar]

22. Acute pancreatitis: a consideration of pancreatic hemorrhage, hemorrhagic, suppurative and gangrenous pancreatitis and of disseminated fat necrosis. Fitz RH.NEngl JMed. 1889;120:181-187. [Google Scholar]

23. Progress in the treatment of acute appendicitis. Meyer KA, Requarth WH, KozollDD.AmJ Surg. 1946;72:830-840. [PubMed] [Google Scholar]

24. Treatment of acute appendicitis. Coldrey E. Br Med J. 1956;2:1458-1461. [PMC free article] [PubMed] [Google Scholar] 